\title{
Following the money? Performance-based funding and the changing publication patterns of Finnish academics
}

\author{
Charles Mathies $^{1}$ (D) $\cdot$ Jussi Kivistö ${ }^{2} \cdot$ Matthew Birnbaum $^{3}$
}

Published online: 6 May 2019

(C) The Author(s) 2019

\begin{abstract}
Research on how performance-based funding influences the behaviour and performance of academics is limited in Europe. In this study, we investigate the changing publication patterns among Finnish academics associated with the introduction of awarding funding for publications within specific journals in the national performance-based funding model. We find evidence, particularly in the social sciences, and to a lesser extent humanities, that Finnish academics increasingly target international (English-language) publication outlets and lowertiered journals. We conclude discussing the possible long-term implications of the current funding formula for both Finnish academia and society.
\end{abstract}

Keywords Performance-based funding · Publications · Bibliometrics · Language of publication · Funding formula

\section{Introduction}

Recent decades have witnessed a growing trend among European nations in designing national performance-based funding (PBF) models to reward specific performance outcomes (Bennetot

Charles Mathies

charles.f.mathies@jyu.fi

Matthew Birnbaum

Matthew.Birnbaum@unco.edu

1 Finnish Institute for Educational Research, University of Jyväskylä, PO Box 35, FI-40014 Jyväskylä, Finland

2 Faculty of Management and Business, Tampere University, Kanslerinrinne 1, FI-33014 Tampere, Finland

3 Department of Higher Education and Student Affairs Leadership, University of Northern Colorado, McKee Hall, Greeley, CO 80639, USA 
Pruvot et al. 2015; de Boer et al. 2015; Jongbloed 2010). State funding allocated through PBF is more than merely a mechanism to allocate financial resources; rather, it provides a tool for institutional managers and policy makers to maximise desired outputs using incentives (Jongbloed 2010). PBF relies on a rather simple expectation of causal behaviours: managerial and administrative responses create incentives that translates into producing improvements in specific university outputs and performance (Kivistö and Kohtamäki 2016). PBF models are seemingly rational and may simplify national budgeting processes, but they may also have long-term consequences for academics and entities relying on their scholarship. Despite widespread adoption of PBF schemes in general, and the use of bibliometric indicators incorporated within these schemes in particular, we still know relatively little about the actual impacts of their use (de Rijcke et al. 2015; Kivistö and Kohtamäki 2016).

To illustrate how a PBF scheme may shape the behaviours of academics, we examine publishing patterns of Finnish academics ${ }^{1}$ between 2012 and 2016, a 5-year period of intense change in the national funding formula. During these years, a modification to elements of the national funding formula significantly rewarded universities more for academic publishing in 'high quality' international outlets, which are frequently in English. A national ('JUFO') classification scheme has determined, since 2012, the quality of publications where all publications receive a rank ranging from 0 (lowest) to 3 (highest). Level 1 is for 'basic' publication channels; level 2 for 'leading' publication channels; and level 3 for 'top' publication channels. Publications evaluated but do not meet levels 1-3 criteria are marked with level 0 (Publication Forum 2018). Since 2015, scientific and other publication outputs account for $13 \%$ of the core funding of Finnish university appropriations (in 2016, approximately 1.6 billion $€$ was appropriated by core funding formula in total; roughly 208 million $€$ based on publications), a dramatic increase from $0.3 \%$ in 2009; making the stakes attached to the model quite significant.

Our overarching aim is to explore the extent is there observable change(s) in Finnish academic publication patterns post introduction of the JUFO classification into the PBF model. We use publication data available through Finland's national education database ('Vipunen') to understand the possible influence of PBF in a context where the funding formula links to a clear publication classification/rating scheme. We conclude the article by considering possible long-term implications for the current funding formula.

\section{Background}

Scientific disciplines and research fields differ from each other in many respects, including their publishing practices. Scholars in the social sciences and humanities (SSH) tend to publish more extensively in books and in domestic languages whereas in the natural sciences, medicine and technology, international publishing, mainly in journals and conference proceedings, is often more dominant (Kyvik 1991; Puuska and Miettinen 2008). There are concerns that bibliometric measurement is shaping particularly younger researchers' choice of publication outlets and focuses them more towards international (English-language) peerreviewed journals (Hammarfelt and de Rijcke 2015). This adaptation is due in large part to the competition for positions and resources increasingly using bibliometric tools in evaluations. Even though the trend favouring more international (English-language) publishing in the SSH




has existed for some time, bibliometric evaluation is accelerating this development (Hammarfelt and de Rijcke 2015).

The increasing use of bibliometric evaluation is not the only cause for the shift in academic publishing patterns. Over the last 20 years, there has been increasing funding opportunities (e.g. ERC, Horizon 2020, and Erasmus+ for Europe) for collaborative cross-border research projects. These funding opportunities have led to internationally focused publications written in a common language, often English. Additionally, researchers wanting to reach a wider audience seek outlets, such as international (English-language) journals, to engage and earn prestige within their academic discipline. Publishing in international (English-language) outlets contributes to the advancement of the 'research field' as a whole while domestic publications have limited readership (Hammarfelt and de Rijcke 2015, p. 71).

Changing publication patterns among Finnish scholars is a current topic of national debate. Finland recognises English as the global language of communication and states the country's multilingualism is a strength and resource (Ministry of Education and Culture 2017). However, supporting Finnish as a language of research, with specific research-related terminology, has been a concern for those who believe the dissemination and popularisation of scholarship in domestic languages is important. As Kuteeva and Airey (2014, p. 546) state, 'language is used in different ways and for different purposes depending on the nature and knowledge-making practices of the academic discipline'. Arguably, publications written in Finnish have a stronger influence in Finnish policymaking and public debate while also being more readily useful as teaching materials (within Finland).

The issue of academic publishing in either Finnish or English appears to be very timely, as it has received a great deal of notice in mainstream media (e.g. Helsingin Sanomat, the largest Finnish newspaper and YLE, the national broadcasting company) as well as in Finnish academic circles in 2018. The debate over the changing status of domestic languages (Finnish and Swedish) in academic publishing has raised concerns that $\mathrm{PBF}$ and bibliometric measurements are favouring publishing practices in 'hard fields'. This, in turn, may affect the preferred language for publication on 'softer' fields, the SSH in particular (Hammarfelt and de Rijcke 2015). If this is an actual trend, Finnish may no longer serve as the most important language of scholarship and academic discourse within the country. In fact, Finnish scientific societies protested the increasing use of international (English-language) publications as the preferred medium; resulting in modifications to the PBF model including inclusion of Finnish-language publications, recognised for their quality, into higher JUFO levels.

\section{Use of indicators in measuring publication productivity}

During the late 1980s and early 1990s, the UK and Australia introduced the first national PBF systems (Aagaard 2015). Currently, a number of countries including the Czech Republic, Denmark, Flanders (Belgium), Hungary, Norway, Poland, Slovakia, Sweden and the UK have incorporated publication productivity indicators into their funding formulas (Bennetot Pruvot et al. 2015; Hicks 2012; Puuska 2014). States seeking to increase research productivity have developed PBF models to incentive particular types of research activities. The use of PBF in research funding aims both to stimulate efficiency (more research with the given level of resources) and excellence or quality (better research with the given level of resources) (Herbst 2007; Hicks 2012). However, previous research (Butler 2003) suggests PBF for research 
encourages an increase in journal publications but in lower impact journals; this is though a contested finding (see van den Besselaar et al. 2017).

Depending on a country's priorities, there exists a diversity of ways to implement PBF for research. Current PBF systems incorporating publications can be placed in one of three categories: (1) 'peer-review-based' models (such as REF in the UK) emphasising excellence, (2) 'citation-based models' utilising databases which contain indexed bibliographic data (Poland, Sweden, Slovakia and Belgium Flanders) emphasising efficiency and (3) 'publication-based models' utilising national publication registers (Norway, Denmark and Finland) emphasising efficiency and excellence. Peer-reviewed models provide substantive indicators for the quality of research publications; however, they are labour intensive and therefore costly. Citation-based models are relatively inexpensive but lack the nuance required to evaluate the quality of discipline-specific publications. Publication-based models group publications into tiers ranked for quality and attempt to mitigate the shortcomings of the other two approaches. Despite their differences in measuring and rewarding the quality of research, each now is thought of as being institutionalised and formalised into 'strong research evaluation systems' (Aagaard et al. 2015; Hammarfelt and de Rijcke 2015).

From the Finnish perspective, Norway's 'Norwegian Publication Indicator' (NPI) and Denmark's 'Bibliometric Research Indicator' (BRI) have been especially influential benchmarks for developing its publication-based rating model. Developed in 2004, NPI was innovative for its classification of publications into two levels or channels: level 1 publications are those for which eligibility criteria include basic norms such as a standard external peerreviewed process, and level 2 publications in the leading outlets in a field, preferably with an international audience. Level 2 channels are exclusive and constitute at most $20 \%$ of a subject area's total scientific publications. This system was developed 'to avoid perverse incentives for researchers to produce more articles with lower quality and to promote publication in channels with high impact' (Aagaard et al. 2014). NPI uses a point system weighted in terms of both level and publication type (e.g. journal articles, articles in anthologies and monographs). By situating itself between cost-intensive peer-review-based models and citation-based models with low coverage of publishing outlets, NPI represented an innovative contribution for the development of PBF for research.

Denmark introduced its BRI system in 2009, which takes into account published peerreviewed research (review articles and monographs) as well as anthology and proceedings papers published by the Danish research institutions. As in Norway, BRI publication channels divide into levels 1 and 2, with designated weights (points) for various publication types (e.g. journal articles, monographs, proceedings papers). Points, assigned in a fractionalized manner, are also given based on the number of collaborating universities, including non-Danish (Giminez-Toledo et al. 2015).

\section{Finnish Publication Forum and PBF}

The role of publications in Finland's PBF model has grown increasingly complex as the weights given to publications types increased over time. Finland has moved towards the examples set by Norway and Denmark by adopting a classification system for evaluating the quality of publications and rewarding those appearing in the most influential academic outlets. In 2009, the Finnish Council of University Rectors (now Universities Finland, UNIFI) formally suggested Finland follow the Norwegian and Danish examples by creating a system 
to (1) improve the quality assessment of scientific publications, (2) provide a tool for the evaluation of the publishing performance of research organisations and (3) increase scholars' awareness of the top ranked publication channels in their disciplinary fields, in order to create an incentive for more ambitious publishing behaviour by researchers (Auranen and Pölönen 2011; Puuska 2014). The following year (2010), the Ministry of Education and Culture (MEC) introduced the 'Publication Forum' (in Finnish, 'Julkaisufoorumi', (JUFO)), a rating system coordinated by the Federation of Finnish Learned Societies (The Federation), the national cooperative body of scholarly and scientific associations/societies. After a 2010-2012 pilot period, the Publication Forum and its Secretariat secured permanent funding from the MEC and became fully incorporated into The Federation. The Federation is now responsible for coordinating, preparing and evaluating the academic publication channels.

Twenty-three discipline-specific expert panels evaluate JUFO level assignments; levels 2 and 3 outlets every 4 years while levels 0 and 1 are yearly (Publication Forum 2018; Pölönen and Ruth 2015). Expert panels are limited to rating up to $20 \%$ of the aggregate publication volume (across all levels) for level 2 and then can only designate up to $25 \%$ of those selected to be level 3 (Publication Forum 2018). The Steering Group of the Publication Forum appoints expert panels for 4-year terms and is composed of representatives of academics and representatives from national agencies, the MEC, and the Academy of Finland, the main research financing body in Finland. Panellists are academics selected for their experience in evaluation of research and competencies. The panellists are predominantly Finnish, as they are supposed to act as representatives of the Finnish science community in their respective field of study and consult their academic communities on the process of JUFO-level assignments.

For assistance in ranking, indicators measuring the impact (Journal Impact Factor, Scimago Journal Rank and Source Normalised Impact per Paper) were available to the panels, along with ratings produced under the corresponding Norwegian and Danish schemes (Pölönen and Ruth 2015). Within the SSH, the panels are able to classify Finnish- and Swedish-language channels as high as level 2. Originally, the inclusion of level 2 domestic publication was not planned, but due to the protests of Finnish scientific societies, representing mainly the SSH, 18 Finnish-language and two Swedish-language journals or publication series were promoted from level 1 to level 2 in 2012 (Puuska 2014; Auranen and Pölönen 2012).

The Finnish Publication Forum classification/rating currently has four levels (levels 0 to 3), or JUFO classifications, that are applied in evaluation of academic scientific 'publication channels' (i.e. journals, book publishers, conferences, as well as printed and digital publication series specialised in the publication of scientific research results). Publications receive a level 0 to 3 based on scientific impact, typical publication practices within specific disciplinary fields and the scientific value enjoyed by the respective channels within the scientific community (Publication Forum 2018). A limited number of academic journals, conferences and book publishers, determined to be of the highest quality and impact, receive level 2 or 3 designations. These are primarily international (English-language) publication channels, with the exception of a small number of level 2 Finnish and Swedish-language outlets. Level 2 publications include leading academic publication channels in which researchers and scholars from different countries publish the best of their research in different disciplines. Level 3 publications include the most wide-ranging and most valued international publication channels within their disciplines; often these have considerable influence in the scientific community. Only refereed scientific publication channels are eligible to be rated in JUFO levels $(0,1,2$ and 3 ). Evaluation of open access journals uses the same criteria applicable to other publication channels (Publication Forum 2018). 
Table 1 Weighting coefficients in funding model (2015-2016)

\begin{tabular}{|c|c|c|c|c|c|}
\hline \multicolumn{2}{|c|}{ Type of publication } & \multicolumn{4}{|c|}{ Coefficient/level } \\
\hline & & Level 3 & Level 2 & Level 1 & Level 0 \\
\hline \multirow[t]{3}{*}{ Refereed } & Articles (A1-A4) & 3 & 3 & 1.5 & 1 \\
\hline & Monographs (C1) & 12 & 12 & 6 & 4 \\
\hline & Edited books (C2) & 0.4 & & & \\
\hline \multirow[t]{4}{*}{ Non-refereed } & Articles (B1-B3, D1-D3, E1) & 0.1 & & & \\
\hline & Reports (D4) & 0.1 & & & \\
\hline & Books (D5, E2) & 0.4 & & & \\
\hline & Edited books (D6, E3) & 0.1 & & & \\
\hline
\end{tabular}

Source: Publication Forum 2018

Beginning in the fall 2015, distinct types of scholarship received an additional weighting coefficient based on the type of publication and the JUFO level (see Table 1). The peerreviewed (refereed) articles in journals, conferences and anthologies published in the level 0 channels had the weighting coefficient 1 , those of the level 1 had the coefficient 1.5 and for the levels 2 and 3, the coefficient was 3. It should be noted that in 2017 (after our sample data), these weightings changed as level 0 now has the weighting coefficient of 0.1 , level 1 has the coefficient of 1, level 2 has the coefficient of 3 and level 3 has the coefficient of 4 (Publication Forum 2018). The weighting coefficient of non-peer-reviewed (scholarly, professional and general public) articles is 0.1 regardless of outlet. The weighting coefficient of peer-reviewed books (monographs) is four times higher than that of articles: in 2015-2016, it was 4 for level 0, 6 for level 1 and 12 for levels 2 and 3. For non-peer-reviewed monographs, as well as all edited volumes, the weight is 0.4 . There is no fractionalization of co-publications at the institutional or author level (Giminez-Toledo et al. 2015; Pölönen 2015).

The Finnish PBF model awards publications 'points' based on its weighting coefficient. The points produced by academics for their annual publications are yearly summed by the MEC and used to allocate a fixed-pool of euros to each institution, essentially incentivising Finnish universities to compete against one another for the same limited resources. The Finnish PBF model has zero-sum game characteristics as the amount of funding caps according to the annual budget constraint; rewards are only available to institutions if increases in performance are higher than competing institutions. The quality and quantity of Finnish academic publications currently (2019) account for $13 \%$ of the total amount available in the funding formula, a large increase from the $0.3 \%$ a decade prior $^{2}$ (see Table 2). Giving such a high weighting for publication points was a dramatic change from the 2010-2012 funding model, which was a more stable input-based indicator 'number of FTE academic staff', thereby increasing further its potential impact.

\section{Methodology and research questions}

Our hypotheses, based on the above literature, are that the introduction of the JUFO classification system altered Finnish academics' publishing behaviours. In particular, we hypothesise

\footnotetext{
$\overline{2}$ The proposed Finnish funding formula starting in 2021 has academic publications account for $14 \%$ of the total amount available in the funding formula.
} 
Table 2 Weighting of publications in the Finnish national funding formula

\begin{tabular}{|c|c|c|}
\hline Years & $\begin{array}{l}\text { Overall weighting of } \\
\text { publications in the formula (\%) }\end{array}$ & Indicators and their subweights \\
\hline $2007-2009$ & 0.3 & Scientific publications per FTE academic staff \\
\hline 2010-2012 & 1.7 & $\begin{array}{l}\text { International peer-reviewed publications }(0.7 \%) \text {, } \\
\text { other scientific publications }(1.0 \%)\end{array}$ \\
\hline 2013-2014 & 13 & $\begin{array}{l}\text { International peer-reviewed publications }(9 \%) \text {, } \\
\text { other scientific publications }(4 \%)\end{array}$ \\
\hline 2015-current & 13 & $\begin{array}{l}\text { Publication Forum rating, weighting } \\
\text { coefficients by publication types }\end{array}$ \\
\hline
\end{tabular}

Source: Publication Forum 2018

a shift occurred within the two refereed scientific publication types (peer-reviewed journals and books) as they carry the most financial (see funding formula, Table 1) and academic (promotion, etc.) reward. In the analysis, we use descriptive statistics to observe changes over time for each of the categories including international/domestic publication, publication type, JUFO classification and academic field. We chose this methodology for multiple reasons.

First, while this approach does not allow for causal inferences, it is important to note that causality between changes in publication patterns and the use of PBF incentivising changes cannot easily be proven (Hammarfelt and de Rijcke 2015; Osuna et al. 2011; Sīle 2016). Second, since we have the entire publication data (population), there is no need to see if there is a difference statistically. As Filho, Paranhos, da Rocha, Batista, da Silva, Santos and Marino (2013, p. 46) argue, 'If the sample size is equal to the size of the population, we cannot expect any error in estimating the true population parameter'. As we have all cases, there is no room for estimating the expected value(s) of the population parameter; it is already present. The important issue, when working with population data, is the magnitude of the difference or change; these represent real differences or changes (Filho et al. 2013). Third, our focus is on general academic areas as opposed to unit-record data as our interest is on broad shifts (increase or decrease) in Finnish academics' publishing behaviours over the 5 years. We are interested in investigating the broad shifts at this time as this represents our initial analysis of the Finnish situation and desire to study further this phenomenon in subsequent studies. Additionally, we lack the space (word count) in this paper to take a more nuanced approached and unpack what more sophisticated data and methods would require.

The following research questions (RQ) for the study are as follows:

RQ1: To what extent are there changes in the percentage of international (Englishlanguage) publications?

RQ2: To what extent are there changes in the publication patterns for refereed journals and books?

RQ3: To what extent are there changes in the publication patterns within disciplines?

RQ4: To what extent are there changes in the publication patterns within JUFO levels?

\section{Data}

We collected data from Vipunen (2018), the reporting portal for educational statistics for the MEC and the Finnish National Board of Education. Data included all scientific academic 
publications (type classification 'A-E') for all Finnish universities $(N=14)$ for the years 2012 to 2016 (note: there have been mergers among Finnish universities during this time and we assign publications to institutions based on current institutional structures). Variables for each publication included being international or domestic, JUFO classification, publication type classification (i.e. peer-reviewed journal article, book, etc.) and field of science. According to Auranen and Pölönen (2014), approximately $75 \%$ of all domestic publications are in Finnish ( $25 \%$ Swedish) while only $4 \%$ of all publications published are in some language other than English, Finnish or Swedish. Therefore, we use the assumption that international publications serve as proxy for a publication in English.

\section{Findings}

We present our findings in a series of tables and figures. Table 3 presents the total number of scientific publications recognised as an international (English-language) or domestic publication. In general, the total number of publications by Finnish universities increased slightly over the 5 years from 37,000 to over 39,000 publications a year. Coupled with this was a steady increase in the percentage of publications in international (English-language) outlets and a corresponding decrease in domestic outlets.

Figure 1 (classification A: peer-reviewed articles) and Fig. 2 (classification C: books) present the number of publications and the percentage of which were international (Englishlanguage) within the two refereed scientific publication types. Figure 1 shows a steady increase in the percentage of peer-reviewed articles that were international (English-language). Additionally, and worth noting, the volume of peer-reviewed articles increased over the 5 years from just under 24,000 articles to nearly 27,500.

Figure 2 shows a large increase in the percentage of books that were international (Englishlanguage). At the same time, there was a substantial decrease in the number of books published over the 5 years.

Table 4 (classification A: peer-reviewed articles) and Table 5 (classification C: books) present the number of publications and the percentage of which were international (Englishlanguage) within the two refereed scientific publication types by academic discipline fields (note: publications with missing field data are included in all fields total). Table 4 shows for the fields of science, technology, medical and health and agricultural and forestry, the percentage of peer-reviewed articles being international (English-language) was relatively stable (i.e. did not change much) and very high (90\% and above) across the 5 years. Social sciences $(8.1 \%)$ and humanities $(5.1 \%)$ experienced increases in the percentage of international (Englishlanguage) publications. The sciences (1504) and medical and health fields (847) experienced substantial increases in the number of peer-reviewed articles over the 5 years.

Table 3 Total publications and location of publication

\begin{tabular}{lllll}
\hline & Domestic & International & Total no. & Percent international \\
\hline 2012 & 13,713 & 23,650 & 37,363 & 63.3 \\
2013 & 12,524 & 24,747 & 37,271 & 66.4 \\
2014 & 11,808 & 25,593 & 37,401 & 68.4 \\
2015 & 11,780 & 26,586 & 38,336 & 69.3 \\
2016 & 12,104 & 27,255 & 39,359 & 69.2 \\
\hline
\end{tabular}




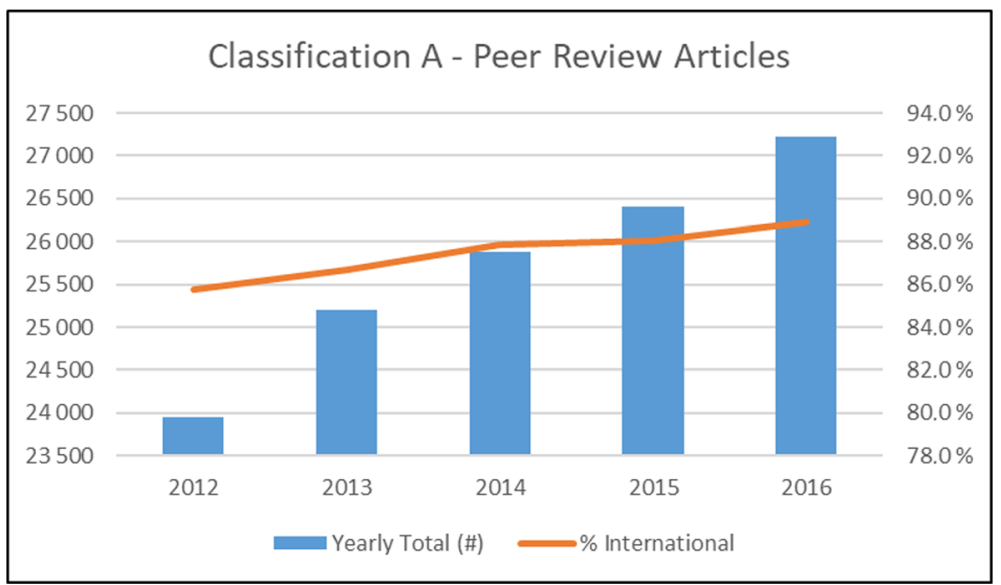

Fig. 1 Number of publications and percent international for peer-reviewed articles

Table 5 shows that the majority (over $80 \%$ ) of books published in a given year were in the $\mathrm{SSH}$. Books in the social sciences experienced the largest change over the 5 years as the number of books published substantially dropped (38\%) while noticeably increasing the percent international (English-language, 23.5\%). Books in the humanities also decreased in the number published, but only had a modest increase in the percent being international (English-language, 3.3\%).

Table 6 presents the number of publications and the percentage international (Englishlanguage) by JUFO classification levels (note: yearly totals include missing JUFO and no rating publications). Three issues emerge with this table. First, level 1 (basic) publications experienced the greatest amount of change over the 5 years. The number of publications in level 1 increased about $50 \%$ going from 10,307 (2012) to 15,725 (2016). In particularly, the last 2 years of the analysis (2015-2016) experienced the largest increase in number of level 1 publications. The percentage of level 1 publications being international (English-language) also steadily increased. Second, the number of level 0 publications (that is, publications which did not meet criteria to be rated) steadily decreased over the 5 years. Third, the number of level

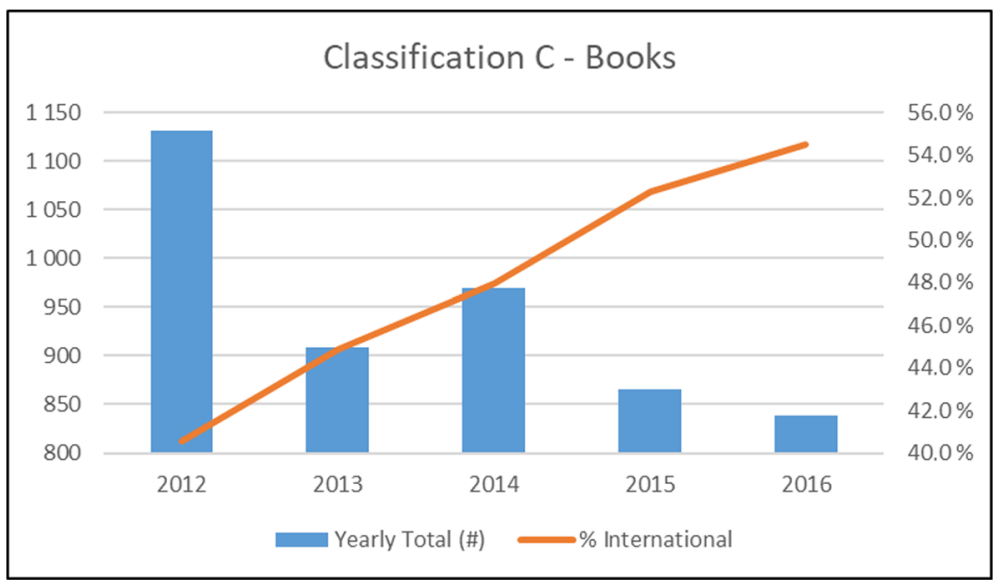

Fig. 2 Number of publications and percent international for books 
Table 4 Classification A-peer-reviewed articles by field

\begin{tabular}{llllllll}
\hline & Sciences & Technology & $\begin{array}{l}\text { Medical } \\
\text { and } \\
\text { health }\end{array}$ & $\begin{array}{l}\text { Agricultural } \\
\text { and forestry }\end{array}$ & $\begin{array}{l}\text { Social } \\
\text { sciences }\end{array}$ & Humanities \\
\hline 2012 & Publications & 7014 & 3348 & 5474 & 517 & 4959 & 2633 \\
& Percent international & 96.4 & 95.9 & 91.7 & 88.8 & 71.1 & 59.1 \\
2013 & Publications & 7710 & 3689 & 5397 & 478 & 5194 & 2738 \\
& Percent international & 96.6 & 96.1 & 91.8 & 91.6 & 76.6 & 54.4 \\
2014 & Publications & 7975 & 3779 & 5830 & 497 & 5212 & 2583 \\
& Percent international & 96.7 & 97.2 & 91.5 & 91.3 & 76.1 & 61.7 \\
& Publications & 8317 & 3777 & 6136 & 479 & 5091 & 2597 \\
& Percent international & 96.9 & 95.6 & 90.8 & 91.2 & 77.6 & 61.9 \\
& Publications & 8518 & 3629 & 6321 & 452 & 5522 & 2757 \\
\hline
\end{tabular}

3 (top) publications decreased around 15 to $20 \%$ in the last 2 years of the analysis (20152016), but the percentage being international (English-language) remained roughly unchanged.

\section{Analysis and discussion}

During the period considered, we observed national trends towards publishing in more international, English-language outlets (RQ1). In particular, this increase was within the two scientific refereed publication types (classifications A, peer-reviewed articles and $\mathrm{C}$, books). The shift though was not uniform across academic disciplines as it was the most pronounced within the social sciences. This finding suggests, given the incentives created in the national funding formula, affirmation of PBF's underlying assumption; financial incentive mechanisms are likely encouraging Finnish academics' efforts to publish in international (Englishlanguage) outlets. During this same 5-year period, there was an increase in the number of publications with an international co-author rising from $26.4 \%$ (2012) to $31.8 \%$ (2016). This increase in international collaborations also likely aided in the increase of international (English-language) publications.

Table 5 Classification $\mathrm{C}$ - books by field

\begin{tabular}{llllllll}
\hline & Sciences & Technology & $\begin{array}{l}\text { Medical } \\
\text { and } \\
\text { health }\end{array}$ & $\begin{array}{l}\text { Agricultural } \\
\text { and forestry }\end{array}$ & $\begin{array}{l}\text { Social } \\
\text { sciences }\end{array}$ & Humanities \\
\hline 2012 & Publications & 119 & 66 & 25 & 18 & 528 & 375 \\
& Percent international & 61.3 & 57.6 & 12.0 & 33.3 & 34.3 & 42.1 \\
2013 & Publications & 81 & 73 & 16 & 8 & 404 & 327 \\
& Percent international & 54.3 & 61.6 & 37.5 & 62.5 & 44.1 & 39.8 \\
2014 & Publications & 108 & 53 & 22 & 9 & 397 & 381 \\
& Percent international & 63.9 & 52.8 & 40.9 & 11.1 & 43.6 & 48.6 \\
2015 & Publications & 80 & 35 & 20 & 6 & 335 & 390 \\
& Percent international & 81.3 & 54.3 & 35.0 & 66.7 & 51.6 & 47.4 \\
& Publications & 90 & 39 & 18 & 6 & 329 & 354 \\
& Percent international & 70.0 & 79.5 & 33.3 & 100 & 57.8 & 45.5 \\
\hline
\end{tabular}


Table 6 Number of publications and percent international by JUFO classification level for peer-reviewed journal articles

\begin{tabular}{llllll}
\hline & 2012 & 2013 & 2014 & 2015 & 2016 \\
\hline Number of yearly publications & 23,945 & 25,206 & 25,876 & 26,402 & 27,218 \\
0= did not meet criteria & 3889 & 3717 & 3352 & 2790 & 2530 \\
Percent international & 75.0 & 80.2 & 81.9 & 75.4 & 81.8 \\
1 = basic & 10,307 & 11,173 & 11,669 & 15,314 & 15,725 \\
Percent international & 83.1 & 83.5 & 84.6 & 87.4 & 88.2 \\
2 leading & 6556 & 6994 & 7252 & 5899 & 6403 \\
Percent international & 89.7 & 89.0 & 90.2 & 91.0 & 89.5 \\
3 top & 3028 & 3296 & 3584 & 2391 & 2559 \\
Percent international & 99.5 & 99.8 & 99.7 & 99.3 & 99.0 \\
\hline
\end{tabular}

To understand these changes, we must make several assumptions about Finnish PBF and the general publication environment during the time considered. The first is that central or senior-institutional managers use similar mechanisms across academic disciplines to incentivise changes in scholarship productively and quality. This assumption seems justified, as publications count the same regardless of discipline, though there is variation among disciplines in their starting point in the percentage of journal articles or books being international (English-language). However, these publications carry more JUFO points, and as such, some disciplines have advantage in this scheme and perform at high levels from the outset. Furthermore, there is evidence that the same financial incentives of the national PBF model have cascaded down to the intra-institutional level. A recent study by Pölönen and Wahlfors (2018) finds many Finnish universities have incorporated the JUFO scheme within their internal funding allocations as well as reward schemes for individual academics. Second, we assume ceteris paribus during the time considered. To our knowledge, no extraneous environmental factors account for our observations. Third, publishing research takes time and there is a usually a time lag of a few months to years between when a project starts and it being published. As such, we would not expect a change in publishing patterns to occur quickly, but rather over time to become a new normative or pattern. From its announcement in 2012, it was clear that the JUFO scheme would become a highly weighted PBF funding criterion by 2015 . Therefore, it is likely we can observe the responses of academics changing their publishing behaviour well before the actual JUFO adoption into the PBF model in 2015. Additionally, the PBF model uses averages of past 3 years in calculation of the indicator scores, so publications published in 2012 were included determining the allocation for 2015, and this was presumably known by Finnish academics.

Given these assumptions, there are several explanations for the observations (RQ2). First, examining the two refereed scientific publication types (peer-reviewed articles and books; Figs. 1 and 2) reveals two different scenarios unfolded. With peer-reviewed articles (classification A), there was a noticeable increase in the number of publications, while at the same time, a steady increase (percentage) of these being international. For books (classification C), however, we find a large decrease in the number of books published, but an extensive increase (percentage) of these being international. This increase is mainly from the fact that there was a large decrease in domestic books (672 in 2012 to 381 in 2016) while international (Englishlanguage) books remained steady (459 in 2012 and 457 in 2016). These findings also suggest Finnish academics shifted towards publishing within peer-reviewed journals at the expense of 
books. This is evident as peer-reviewed journal articles made up 64\% of all publications in 2012 and steadily rose to over $69 \%$ in 2016.

Second, with respect to RQ3, we observe an overall increase in international (Englishlanguage) publications that was primarily due to changes in publications within the social sciences and to a lesser extent, in the humanities (see Tables 4 and 5). The relatively high ratio of international (English-language) to domestic publications among natural sciences, engineering and technology, medical and health sciences, and agricultural and forestry fields, as well as the stability of these figures, suggests these disciplines were publishing heavily in international (English-language) outlets prior to the Finnish reforms being enacted. Because English has been the 'language of science' for some time, this is not surprising. Scholarship in these fields is for global consumption and often requires international expertise for proper peer evaluation (Kuteeva and Airey 2014). If this explanation is correct, we can predict that the ratio of international (English-language) to domestic publications in these fields to remain stable until new incentivising mechanisms are enacted promoting different publication outcomes.

Finnish academics in the SSH fields, two areas that published extensively in domestic outlets prior to the reforms, appear to be the most impacted by the new PBF incentives. The trends towards publishing more in international (English-language) journals follow the large increase in publication weighting within the funding formula; it appears to have occurred quickly in both fields. Perhaps, the best explanation for this change is that the managerial mechanisms associated with PBF were effective for these fields, although causal direct links to behavioural changes are not clear and outside the scope of this paper. We note again that our analysis is on general academic areas and the broad shifts (increase or decrease) in Finnish academics' publishing behaviours. As such, we are also likely not picking up subfield differences within the larger general academic areas like SSH. While the effect is likely the strongest for SSH fields, it is very likely they are not behaving as a single coherent group.

Third, with respect to RQ4, we observe changes in publications identified by their JUFO levels (see Table 6). The number of publications in peer-reviewed journals with level 2 and level 3 designations decreased modestly in the last 2 years of observations (2015 and 2016). These are the most selective journals with high rejection rates but also offer the highest financial incentives. Meanwhile, the number of level 1 publications noticeably increased over the 5 years (10,307 in 2012 to 15,725 in 2016) while simultaneously increasing in the percent international (English-language, $83.1 \%$ in 2012 to $88.2 \%$ in 2016). Lastly, we observe a 35\% decrease in the number of level 0 publications with a slight increase in the percent of which are international. These results suggest that level 1 (basic) peer-reviewed journals became the primary target outlet and efforts to publish in this category were increasingly towards international (English-language) journals. A likely explanation for this is that some academics might find the increased likelihood for rejection from a level 2 or level 3 journal not worth the risk and opt to submit their work to a level 1 journal instead (i.e. weighing the trade-off between amount of work and likely reward). At the same time, academics find submitting to level 0 journals not worth the financial nor academic reward and are opting increasingly to submit to a level 1 journal.

Coupled with the previous observation of the increase in internationality of publications within social sciences and to a lesser extent the humanities' fields, the increased numbers and internationality of level 1 peer-reviewed articles suggest Finnish academics, in particularly within these two fields, reacted to the PBF changes by writing and publishing more in level 1 international (English-language) outlets. The increases in level 1 international (Englishlanguage) publications are likely influenced by the fact there exists only 242 (140 Finnish, 
102 Swedish) level 1 ranked domestic outlets, but 15,295 English-language level 1 outlets (Publication Forum 2019). Within SSH, there are 223 domestic (127 Finnish, 96 Swedish) level 1 outlets and 6954 English-language outlets at level 1 (Publication Forum 2019). In summary, a likely explanation is Finnish academics reacted to the new incentive structure by increasingly foregoing JUFO levels 0,2 and 3 peer-reviewed journals (classification A) and books (classification C). Instead, they are submitting (and publishing) their work to level 1 journals and increasingly to international (English-language) outlets.

\section{Conclusions and implications}

Finland implemented the PBF to influence specific higher education outcomes it deems important, including scholarly publication. By increasing the weight it gives to scholarly publications to $13 \%$ of the funding formula allocating the core funding to universities, the Finnish MEC has signalled its interest in having institutions identify mechanisms to incentivise academics to publish increasingly in international (English-language) outlets. This is similar to Hammarfelt and de Rijcke (2015) and van den Besselaar et al. (2017) findings of academics increasingly publishing more in international rather than domestic or regional peer-reviewed journals. While isolating specific factors behind the change of publication patterns is complex, it does appear the PBF is altering the behaviours of scholars in the social sciences and to a lesser extent in the humanities. However, the increasing number of publications with international co-authors also likely contributed to this shift as well. While these changes are modest now, existing PBF incentives may lead to unintended long-term consequences for the dissemination of scholarship in Finnish. We consider plausible consequences of further shifts to international (English-language) outlets from two perspectives: Finnish academics and domestic (Finnish-language) outlets.

PBF relies on a logic that behaviours adjust in response to incentives, both at the level of universities and individuals. Even though causality between changes in publication patterns and the use of PBF incentivising these changes cannot easily be proven (Hammarfelt and de Rijcke 2015; Osuna et al. 2011; Sîle 2016; Aagaard and Schneider 2017), it is reasonable to assume that they are at least, to some extent, associated with each other. The changing publication patterns of Finnish academics, specifically those in the SSH, support the underlying logic of PBF but also suggest individuals are using similar rational logic when considering which publication outlets to target for their work. In other words, Finnish academics now give time and energy to identifying an optimal balance between academic rigour and prestige (e.g. JUFO level), the incentive structures, and the time required to produce scholarship. While most academics with publication responsibilities already considered the intended audience of their work, possible publication outlets, and balancing the effort required and odds of success to publish, the introduction of the JUFO classifications into the PBF likely added an additional layer(s) to this activity. In general, manuscripts with few opportunities for publication appear to be less desirable than scholarship with many opportunities.

In the Finnish case, it appears this has resulted in a shift away from level 2 and 3 journals. Due to the hierarchical nature of academic journals, this may seem like faulty logic if a scholar desires to publish in the highest ranked outlets. It is worth noting that scholarship not accepted into level 2 and level 3 outlets can still submit to level 1 outlets. The decreases in level 0 publications also suggest that many of these same academics are seeking outlets that have a minimum level of academic prestige (i.e. any journal will not work). This result in some ways 
seems to split the contested differences between Butler's (2003, increase in publications albeit in lower impact journals) and van den Besselaar et al. (2017, increase in publications and in 'quality' publications) findings in Australia post PBF introduction. The level 1 outlets, which is also the largest pool of journals, has significantly more international (English-language) than domestic options. It appears, in weighing the odds of getting a manuscript published, the effort involved to do so and the reward involved, Finnish academics have increasingly focused on level 1 international (English-language) journals.

Assuming the weighting and rating of publications in the current PBF structure continues; it is likely that Finnish social science and humanity scholars will continue to factor incentives into their decisions about potential scholarship outlets. The large number of international (English-language) outlets available would lead rationale actors increasingly to write in English. The drop in the overall number of Finish language publications immediately following the incentive change suggests this logic maybe already influencing Finnish scholars, and in particular the social sciences the most. The result is Finnish academics from SSH, the individuals most likely to write scholarship in Finnish, are publishing less in Finnish.

Evaluating the generalizability of these findings is difficult since there exists a scarcity of cross-country comparative studies of SSH publication patterns (see Kulczycki et al. 2018; Nordforsk 2018; Ossenblok et al. 2012). Nevertheless, our findings seem to be consistent with similar developments in other countries utilising bibliometrics as a driver in PBF for research. Ossenblok et al. (2012) found publishing in English within SSH increased in Belgium (Flanders) and Norway after adopting a PBF system. In Norway, SSH researchers increasingly published more in selective international (English-language) outlets rather than less selective domestic ones. As in Finland, PBF in Flanders and Norway have a direct influence on the research income of the universities involved, and universities translate the incentives of the system towards departments and individuals, thus influencing publication patterns.

The changes associated with the incentives to publish in international (Englishlanguage) outlets may also affect the Finnish-language journals and other channels for scholarly dissemination if the observed trends continue. If fewer academics are choosing to write in Finnish and those that do seek level 1 or higher outlets, it seems likely that domestic level 0 outlets will become archaic, as Finnish academics will only submit scholarship to these outlets if rejected from a higher quality Finnish journal(s). However, Finnish academics who seek to publish in the highest quality outlets will increasingly write for international (English-language) publications to increase opportunities of publication in level 1, 2 or 3 outlets. Finnish-language scholarly outlets will likely come under scrutiny because of reduced interest among scholars and their JUFO level might go down as a reaction to the perceived quality of the publication. This may though just be a temporary phenomenon and deserves close monitoring by the Publication Forum. It may take years for academics in the social sciences, and to a lesser extent in the humanities, to transition to writing completely in English but once the process is underway, it may be difficult to reverse without significant changes to the incentive structure. This could possibly lead to a downward spiral of reductions in the number of Finnish-language publications if interventions, perhaps in the form of specific incentives, are not undertaken.

A challenge for this study and we imagine for Finnish scholars and institutional managers is the publication model's continual evolution and increasing complexity. It appears changes to the model, intended to fine-tune it, placed value on specific types of scholarship. However, if scholars and institutional managers are making decisions about publication outlets and 
incentives, these ongoing changes may frustrate future planning and call into question the need for additional changes. Given how quickly publications became the basis for a significant portion of the national funding model, we imagine institutions with few highly productive scholars are quickly attempting to identify ways to increase scholarly productivity. This could lead to mission creep and fewer resources for traditional programmes that may not historically have high bibliometric measured scholarship productivity.

Sivertsen (2016) argues SSH would lose great deal of their reason to exist if they will disconnect themselves from the national culture and society. At the same time, also according to Sivertsen (2016), publishing at the international level is necessary to keep connected with international peers and wider scientific of the field. The challenge of publication language, therefore, is not about 'either-or', but it is about finding an appropriate balance in domestic and international (English-language) publishing efforts. Given the speed and the general direction of changes in publication patterns, the concerns among those who believe Finland benefits from Finnish-language scholarship are well supported (Puuska 2014). As scholars in the SSH increasingly publish in English, their work will be less likely to influence Finnish policy and public debate. Their work will also be less likely to capture traditional Finnish ideas or expressions that do not have English-language equivalents. While it is extreme to suggest that Finnish will collapse as a language of research and science, it does appear the current incentive structures are placing increasing pressure on Finnish scholars to disseminate their ideas in English. In the long term, this may create tensions between the country's commitment to a multilingual citizenry (Ministry of Education and Culture 2017) and its higher education funding model.

Our findings suggest Finnish PBF incentives are likely affecting publication patterns among Finnish academics but perhaps not completely in the ways anticipated. Increasing our understanding of how PBF incentivises behaviour provides those concerned with their impact necessary data to alleviate the possible harm created. This creates opportunities, at best, to correct the unintended consequences, and at worst, to mitigate the damages created. It is clear other drivers than JUFO classification system and its attachment to funding model SSH have influenced changes in publication patterns. This includes, but is not limited to, the increasing internationalisation of research networks, attempts to increase personal $h$-index (international, English-language, publications are often more cited than domestic ones), peer pressure (publishing in English is an academic merit domestically), eligibility to gain international research funding, and so on.

While we are not claiming a causal relationship exists between PBF formulas and the publication patterns, we do observe convergence between the changes in the publication patterns with the priorities set by the PBF publication indicator. While our analysis is only for 5 years (2012-2016) and a longer time series ${ }^{3}$ would allow for a more robust analysis on the impact of the introduction of JUFO into the PBF on publishing behaviours, the results at least suggest an indication of some influence the PBF has on publication patterns and especially in the SSH fields. Finland has demonstrated its willingness to adopt and modify funding models rewarding desired outcomes in the past and we suspect additional changes may seek to address the current possible shortcomings. Whatever the adopted modifications are, it seems likely that Finnish academics will similarly modify their efforts to help ensure their scholarship efforts maximise funding.

\footnotetext{
${ }^{3}$ Data used is publicly accessible as earlier data is not easily accessed.
} 


\section{Funding}

Dr. Mathies received funding from the Academy of Finland (Academy Research Fellowship) to support his research Grant \#310508. Dr. Birnbaum received an institutional grant from the University of Northern Colorado to participate in the study.

Acknowledgements Open access funding provided by University of Jyväskylä (JYU).

\section{Compliance with ethical standards}

Conflict of interest The authors declare that they have no conflict of interest.

Open Access This article is distributed under the terms of the Creative Commons Attribution 4.0 International License (http://creativecommons.org/licenses/by/4.0/), which permits unrestricted use, distribution, and reproduction in any medium, provided you give appropriate credit to the original author(s) and the source, provide a link to the Creative Commons license, and indicate if changes were made.

\section{References}

Aagaard, K. (2015). How incentives trickle down: Local use of a national bibliometric indicator system. Science and Public Policy, 42, 725-737.

Aagaard, K., \& Schneider, J. (2017). Some considerations about causes and effects in studies of performancebased research funding systems. Scientometrics, 11, 923-926.

Aagaard, K., Bloch, C. W., Schneider, J. W., Henriksen, D., Lauridsen, P. S., \& Ryan, T. K. (2014). Evaluation of the Norwegian Publication Indicator. Oslo: Norwegian Association of Higher Education Institutions.

Aagaard, K., Bloch, C., \& Schneider, J. (2015). Impacts of performance-based research funding systems: The case of the Norwegian Publication Indicator. Research Evaluation, 24, 106-117.

Auranen, O., \& Pölönen, J. (2011). Vastaus Jarno Valkoselle ja Veera Kinnuselle [A reply to Jarno Valkonen and Veera Kinnunen]. Sosiologia, 48(2), 163-164.

Auranen, O. \& Pölönen, J. (2012). Tieteellisten julkaisukanavien tasoluokitus: Julkaisufoorumihankkeen (20102012) loppuraportti [Ratings of scientific publication channels: Final report on Publication Forum Project (2010-2012)]. Helsinki: Tieteellisten seurojen valtuuskunta.

Auranen, O., \& Pölönen, J. (2014). Julkaisufoorumi-luokitus ja kansallinen tieteellinen julkaiseminen [Publication Forum rating and national scientific publishing]. Informaatiotutkimus, 33(3).

Bennetot Pruvot, E., Claeys-Kulik, A.-L., \& Estermann, T. (2015). Designing strategies for efficient funding of universities in Europe. Brussels: European University Association.

Butler, L. (2003). Explaining Australia's increased share of ISI publications - The effects of a funding formula based on publication counts. Research Policy, 32, 143-155.

de Boer, H., Jongbloed, B., Benneworth, P., Cremonini, L., Kolster, R., Kottmann, A., \& Vossensteyn, H. (2015). Performance-based funding and performance agreements in fourteen higher education systems. Enschede: Centre for Higher Education Policy Studies.

de Rijcke, S., Wouters, P. F., Rushford, A. D., Franssen, T. P., \& Franssen, B. (2015). Evaluation practices and effects of indicator use-A literature review. Research Evaluation, 25(2), 161-169.

Filho, D., Paranhos, R., da Rocha, E., Batista, M., da Silva, J., Santos, M., \& Marino, J. (2013). When is statistical significance not significant? Brazilian Political Science Review, 7(1), 31-55.

Giminez-Toledo, E., Mañana-Rodriguez, J., Engels, T., Ingwersen, P., Pölönen, J., Sivertsen, G., \& Zuccala, A. A. (2015). The evaluation of scholarly books as research output. Current developments in Europe. In A. A. Salah, Y. Tonta, A. A. Akdag Salah, C. Sugimoto, \& U. Al (Eds.), Proceedings of the 15th International Society for Scientometrics and Informetrics Conference, Istanbul, Turkey, 29th June to 4th July, 2015 (pp. 469-476). Bogazici University. 
Hammarfelt, B., \& de Rijcke, S. (2015). Accountability in context: Effects of research evaluation systems on publication practices, disciplinary norms and individual working routines in the faculty of Arts at Uppsala University. Research Evaluation, 24(1), 63-77.

Herbst, M. (2007). Financing public universities. The case of performance funding. Higher Education Dynamics Series. Vol. 18. New York: Springer.

Hicks, D. (2012). Performance-based university research funding systems. Research Policy, 41(2), $251-261$.

Jongbloed, B. (2010). Funding higher education: A view across Europe. Brussels: European Centre for Strategic Management of Universities.

Kivistö, J., \& Kohtamäki, V. (2016). Does performance-based funding work? Reviewing the impacts of performance-based funding on higher education institutions. In R. Pritchard, A. Pausits, \& J. Williams (Eds.), Positioning higher education institutions: From here to there (pp. 215-226). Rotterdam: Sense Publishers.

Kulczycki, E., Engels, T. C. E., Pölönen, J., Bruun, K., Dušková, M., Guns, R., Nowotniak, R., et al. (2018). Publication patterns in the social sciences and humanities: Evidence from eight European countries. Scientometrics, 116, 463-486.

Kuteeva, M., \& Airey, J. (2014). Disciplinary differences in the use of English in higher education: Reflections on recent language policy developments. Higher Education, 67(5), 533-549.

Kyvik, S. (1991). Productivity in academia: Scientific publishing at Norwegian universities. Oslo: Universitetsforlaget.

Ministry of Education and Culture. (2017). Multiculturalism as strength. http://minedu.fi/documents/1410845 /5875747/Multilingualism_tiivistelma.pdf/be86bffa-d55f-4935-bff4-2fd150c82067/Multilingualism_ tiivistelma.pdf. Accessed Dēember 2017.

Nordforsk. (2018). Comparing research in social sciences and the humanities in the Nordic countries-An explorative study. https://www.nordforsk.org/en/publications/publications_container/comparing-research-insocial-sciences-and-the-humanities-in-the-nordic-countries-an-explorative-study/download. Accessed March 2018.

Ossenblok, T. L. B., Engels, T. C. E., \& Sivertsen, G. (2012). The representation of the social sciences and humanities in the Web of Science-A comparison of publication patterns and incentive structures in Flanders and Norway (2005-9). Research Evaluation, 21, 280-290.

Osuna, C., Cruz-Castro, L., \& Sanz-Menéndez, L. (2011). Overturning some assumptions about the effects of evaluation systems on publication performance. Scientometrics, 86(3), 575-592.

Pölönen, J. (2015). Suomenkieliset kanavat ja julkaisut Julkaisufoorumissa [Finnish language publication channels and publications in the Publication Forum]. Media \& Viestintä, 38(4), 237-252.

Pölönen, J., \& Ruth, A.-S. (2015). Final report on 2014 review of ratings in Publication Forum. Helsinki: Federation of Finnish Learned Societies.

Pölönen, J., \& Wahlfors, L. (2018). Julkaisufoorumiluokituksen käyttö yliopistoissa [The use of Publication Forum classification in universities]. Hallinnon Tutkimus, 1, 7-21.

Publication Forum. (2018) Publication Forum and evaluations. http://www.julkaisufoorumi.fi/en. Accessed March 2018.

Publication Forum. (2019). Publication channel search. https:/www.tsv.fi/julkaisufoorumi/haku.php?lang=en. Accessed February 2019.

Puuska, H-M. (2014). Scholarly publishing patterns in Finland. A comparison of disciplinary groups. Doctoral dissertation. Tampere: Tampere University Press.

Puuska H.-M., \& Miettinen, M. (2008). Julkaisukäytännöt eri tieteenaloilla [Disciplinary differences in publishing practices]. Opetusministeriön julkaisuja 2008:33. Helsinki: Opetusministeriö.

Sīle, L. (2016). Elusive quality of educational research in a context of bibliometrics-based research funding systems: The case of the University of Gothenburg 2005-2014 (MA dissertation). Gothenburg: University of Gothenburg. http://hdl.handle.net/2077/45954. Accessed March 2018.

Sivertsen, G. (2016). Patterns of internationalization and criteria for research assessment in the social sciences and humanities. Scientometrics, 107(2), 357-368.

van den Besselaar, P., Heyman, U., \& Sandström, U. (2017). Perverse effects of output-based research funding? Butler's case revisited. Journal of Informetrics, 11, 905-918.

Vipunen. (2018). Korkeakoulutuksen yhteiset ja t\&k-toiminta-Julkaisut [Higher education and R\&D activitiesPublications]. https://vipunen.fi/fi-fi/kkyhteiset/Sivut/Julkaisut.aspx. Accessed November 2018.

Publisher's note Springer Nature remains neutral with regard to jurisdictional claims in published maps and institutional affiliations. 